\title{
Lumen-apposing metal stent for the creation of an endoscopic duodenojejunostomy to facilitate bile duct clearance following Roux-en-Y hepaticojejunostomy
}

A 52-year-old woman with history of bile duct injury following cholecystectomy and previous Roux-en-Y hepaticojejunostomy was admitted because of cholangitis. Her work-up revealed a 7-mm stone in the right intrahepatic duct on magnetic resonance cholangiopancreatography (MRCP). An initial single-balloon enteroscopy-assisted endoscopic retrograde cholangiopancreatography (ERCP) revealed independent right and left hepaticojejunostomies and bilateral strictures. A large right intrahepatic filling defect was identified on an occlusion cholangiogram ( $\triangleright$ Fig.1). Bilateral dilation of the anastomosis was performed with an 8-mm hydrostatic balloon, but the stone could not be removed and two plastic biliary stents $(7 \mathrm{~F} \times 5 \mathrm{~cm})$ were placed.

Contrast injection into the biliopancreatic limb showed that it was closely approximated to the duodenal bulb and therefore suitable for an endoscopic ultrasound (EUS)-guided duodenojejunostomy (EUS-DJ) to facilitate access to the afferent limb and complete clearance of the bile duct using the appropriate accessories. A single-balloon enteroscope fitted with a cap was advanced to the hepaticojejunostomy. The afferent limb was filled with diluted contrast mixed with $1 \%$ methylene blue, and 2 mg of glucagon was given intravenously to slow peristalsis. A linear echoendoscope was then advanced to the duodenal bulb and the distended jejunal limb was identified and punctured using a 19-gauge fineneedle aspiration (FNA) needle. Aspiration of blue-tinged fluid confirmed the correct location in the afferent limb. A cautery-enhanced lumen-apposing metal stent (LAMS; $15 \mathrm{~mm} \times 10 \mathrm{~mm}$ ) was deployed, thereby creating a duodenojejunostomy ( $\triangleright$ Video 1$)$.

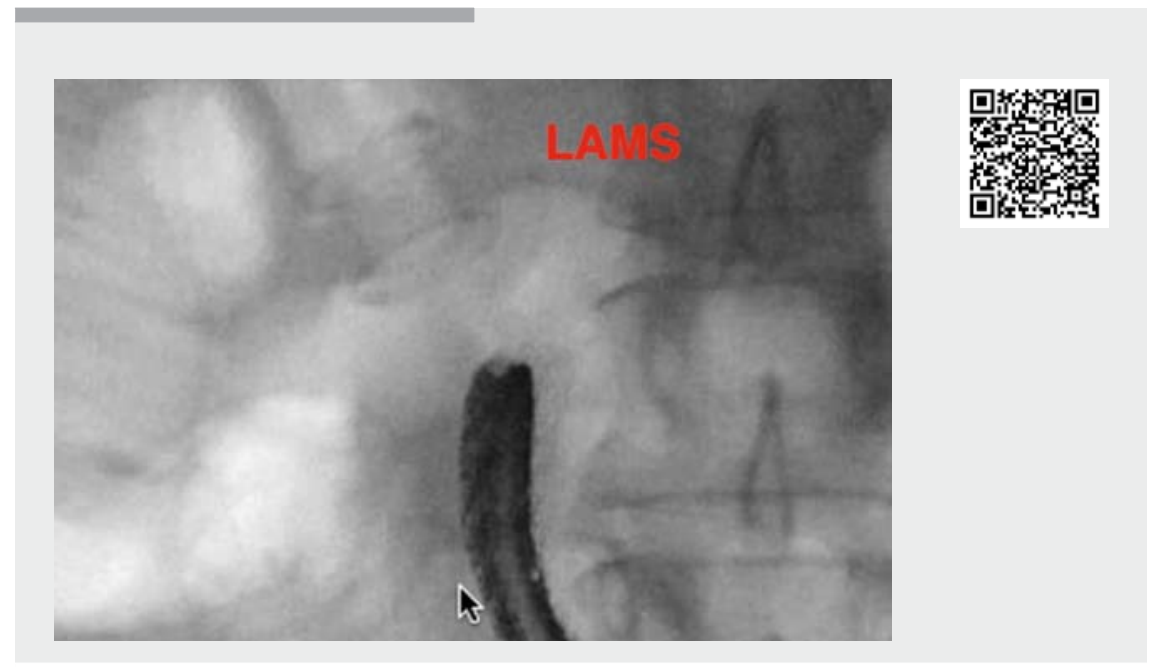

Video 1 Endoscopic ultrasound-guided duodenojejunostomy in a patient with a Rouxen-Y hepaticojejunostomy and right intrahepatic duct stone.

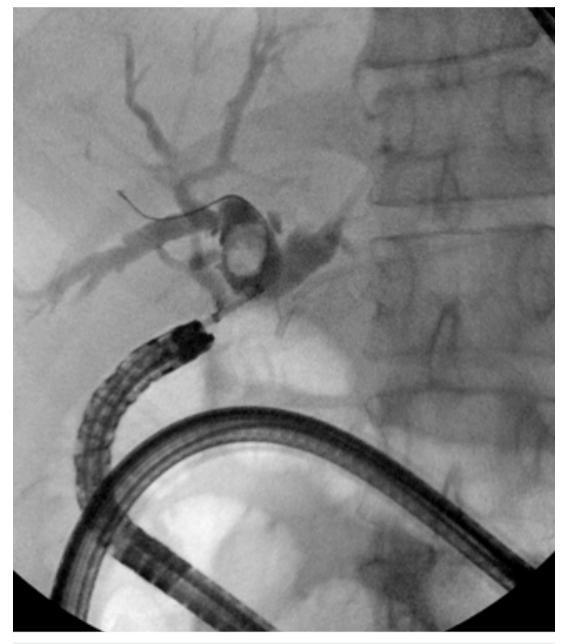

- Fig. 1 Occlusion cholangiogram during enteroscopy-assisted endoscopic retrograde cholangiopancreatography showing a large right intrahepatic filling defect.

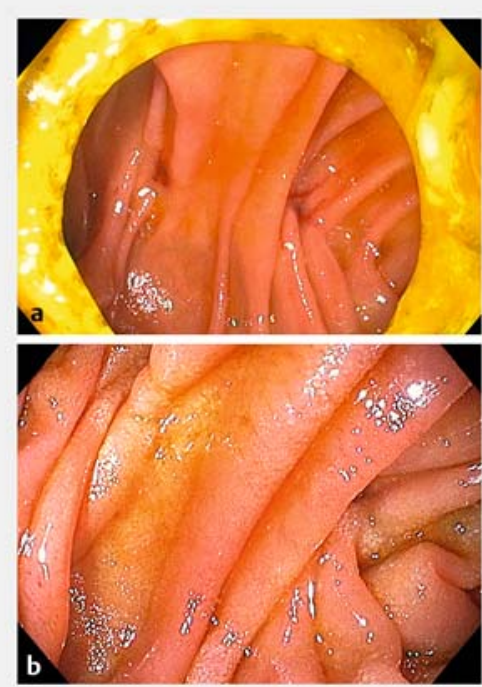

- Fig. 2 Endoscopic views showing: a the patent duodenojejunostomy lumenapposing metal stent; $\mathbf{b}$ the independent right/left hepaticojejunostomy. 


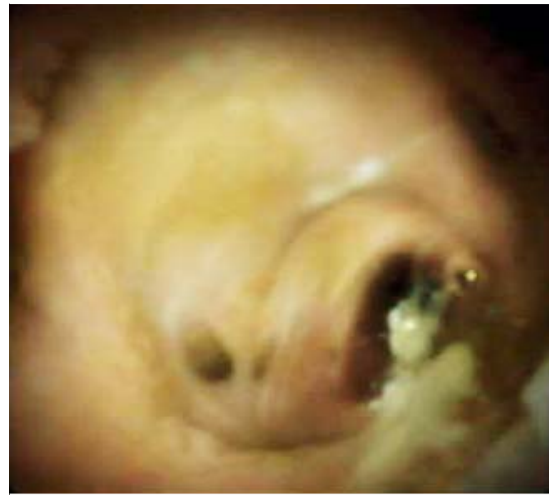

- Fig. 3 Digital cholangioscopic view showing no evidence of persisting intraductal stones.

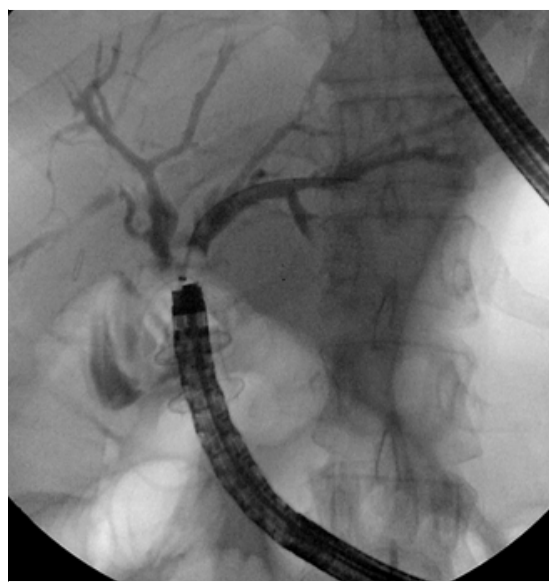

- Fig.4 Cholangiographic view during follow-up endoscopic retrograde cholangiopancreatography performed through the duodenojejunostomy. showing no residual right or left intrahepatic stones.
The patient returned 4 weeks after the procedure for an ERCP with cholangioscopy. A therapeutic upper gastrointestinal endoscope was advanced to the duodenojejunostomy ( $\mathbf{F i g . 2} \mathbf{a}$ ) and the hepaticojejunostomy was identified 1$2 \mathrm{~cm}$ distally ( $\mathbf{F i g} \mathbf{2} \mathbf{b}$ ). A digital singleoperator cholangioscope was advanced into the right anterior, mid, and posterior branches of the right intrahepatic duct. Sludge but no stones were seen in the posterior branch ( $\triangleright$ Fig. $\mathbf{3}$ ). The left intrahepatic duct was normal. The patient underwent a further MRCP and a follow-up ERCP after 4 weeks with no additional stones identified ( $\triangleright$ Fig.4), and the LAMS was removed. To date, the patient has remained asymptomatic.

Endoscopy_UCTN_Code_TTT_1AS_2AD

\section{Competing interests}

Mouen A. Khashab is a consultant for Boston Scientific, Medtronic and Olympus.

The remaining authors have no competing interests to disclose.

The authors

Olaya I. Brewer Gutierrez, Thomas Runge, Yervant Ichkhanian, Kia Vosoughi, Mouen A. Khashab

Division of Gastroenterology and Hepatology, Johns Hopkins Medical Institutions, Baltimore, Maryland, USA

\section{Corresponding author}

Mouen A. Khashab, MD

Johns Hopkins Hospital, Sheikh Zayed Bldg, Division of Gastroenterology and Hepatology, 1800 Orleans Street, Suite 7125G, Baltimore, MD 21287, USA

Fax: +1-443-683-8335

obrewer1@jhmi.edu

\section{Bibliography}

DOI https://doi.org/10.1055/a-0965-6402

Published online: 24.7.2019

Endoscopy 2019; 51: E400-E401

(c) Georg Thieme Verlag KG

Stuttgart · New York

ISSN 0013-726X

\section{ENDOSCOPY E-VIDEOS \\ https:/|eref.thieme.de/e-videos}

回题 Endoscopy E-Videos is a free access online section, reporting 靣和: on interesting cases and new techniques in gastroenterological endoscopy. All papers include a high quality video and all contributions are freely accessible online.

This section has its own submission website at

https://mc.manuscriptcentral.com/e-videos 